\title{
Mobile talent or privileged sites? Making sense of biotech knowledge worker mobility and performance in Sweden
}

\author{
H. Mattsson \\ Dept. of Social \& Economic Geography and CIND, Uppsala Universitet, Sweden \\ Received: 15 December 2006 - Published in Soc. Geogr. Discuss.: 16 January 2007 \\ Revised: 16 November 2007 - Accepted: 26 November 2007 - Published: 20 December 2007
}

\begin{abstract}
Great hope is currently put in biotechnological innovation to create economic growth and ensure future competitiveness of regions and nations. For some years, economic geography and economics have been focusing on privileged sites when explaining geographical variances in actors' ability to innovate: e.g. regional innovation systems, clusters, industrial districts and creative milieus. In such explanations, the basic notion is that certain sites, as a result of their privileged configuration, relative position and history, tend to support innovation to a higher degree than other milieus. Lately, however, there has been a shift in focus within some research communities towards what could be called a "talented people" explanation. The problem for those interested in biotech innovation policy and in the larger question about exactly how biotechnological knowledge production takes place, is that this debate offers two diametrically different understandings of (i) the geography of innovation and, in turn, (ii) how to actually design innovative spaces or increase rates of innovation. According to the talented people argument, innovation policy should be focusing on designing attractive spaces in which creative people want to live, while the privileged sites argument instead focuses on figuring out how to design creative spaces. In this paper, a unique dataset is used to explore to what extent the two debating concepts, privileged sites and talented people, can explain what is going on in biotech landscapes in Sweden.
\end{abstract}

\section{Introduction}

In recent years it has been suggested that the key determinant of long term competitiveness in global economic landscapes is no longer "cost efficiency" but "innovation" (Malmberg and Maskell, 1997). Indeed, for some time now, it has been

Correspondence to: $\mathrm{H}$. Mattsson

(henrik.mattsson@kultgeog.uu.se) argued and convincingly shown across economic disciplines that the innovation thesis, which emphasises the ability of economic actors to develop and implement new products, processes and practices, is helpful in explaining competitiveness and growth in the globalising economy (Maskell and Malmberg, 1999; Edquist, 1997; Braczyk et al., 1998; Lundvall, 1992, 2005; Cooke, 2002).

Concrete effects of this theoretical shift have become evident lately. For example, in many countries academics, businesses and governments have identified national innovation systems (Lundvall, 1992) and clusters (Porter, 1998), and great hope is currently put in these to create economic growth and ensure future competitiveness of the particular region in which they are situated. As can be seen most clearly in the restructuring of government agencies and reformulations of development policies, this interest and hope is taking concrete form in policy apparatuses, which are slowly pulling away from national policies aiming predominantly at macroeconomic stability to include a concern for the role of the micro-economic climate for enhancing rates of innovation and designing good breeding grounds for innovative firms and activities: e.g. clusters, science parks and creative milieus (Hallin and Östhol, 2004; Malmberg, 2002). With this comes a sharper focus on individuals (e.g. innovators and entrepreneurs). Also, as a part of this shift, a special liking has developed for new technologies and there is today a strong fascination among mentioned groups for the new businesses and industries created by such technologies. Biotech ${ }^{1}$ is arguably the latest idol of the crowd, and nations and regions now commonly desire to become a biotech hotspot - that is, a space swarming with biotech activities that create large amounts of economic growth and competitiveness (Rinaldi, 2006).

\footnotetext{
${ }^{1}$ In this paper, "biotechnology" refers to the specific technology, while "biotech" is used to describe the wider activities related to it.
} 
However, despite the hopes of policymakers and innovation theorists, it has proven difficult to artificially create efficient biotech spaces, or even to support and develop milieus that exist already in at least some embryonic form. To some extent, this is due to the very nature of innovation processes; innovation is a spatially promiscuous and unruly phenomenon which does not care much for the territorial logic of policy bodies (Mattsson, 2006). However, it is also due to deficits in our theoretical understanding of how different innovation components interact in time and space. While scholars agree that innovation and its related processes of knowledge creation and acquisition are best conceived of in systemic terms, as being part of a context, theory concerning the spatial scope of innovation contexts and systems is literally and figuratively all over the place. A central area of debate is about privileged sites versus talented people - and, in turn, about creative spaces versus attractive spaces.

For some years now, economic geography and economics have been focusing on privileged sites when explaining geographical variances in actors' ability to innovate: e.g. regional innovation systems, clusters, industrial districts, creative milieus, etc (Marshall, 1920, 1960; Asheim, 1996; Storper, 1992; Malmberg and Maskell, 1997; Scott, 1988). In such explanations, the basic notion is that certain sites, as a result of their privileged configuration, relative position and history, tend to support innovation (and the innovativeness of individuals) to a higher degree than other milieus. Lately, however, there has been a shift in focus within some research communities towards what could be called a "talented people" explanation, which is especially evident in Richard Florida's work about the rise of the creative class (Florida, 2002a, b), but also evident in research on the importance of labour mobility in cluster development (Almeida and Kogut, 1999; Power and Lundmark, 2007²). This type of economic geographic research focuses less on the dynamics of spatial settings - i.e. creative spaces - and more on the ability of sites to attract and retain talent - i.e. attractive spaces. With this focus, sites arguably take the back seat and are recast as more or less popular 'playgrounds' for the innovative elite. The spatial scale, however, shrinks; while privileged sites like clusters or innovation systems can span rather large geographical areas, attractive spaces à la Richard Florida are smaller and more local - often centred in certain neighbourhoods, rarely expanding beyond a city-region.

While these two perspectives in many ways are mutually reinforcing rather than polemic, the fact that they offer two diametrically different understandings of (i) the geography of innovation and, in turn, (ii) how to actually design innovative spaces or increase rates of innovation, causes a dilemma for those interested in biotech innovation policy and in the larger

\footnotetext{
${ }^{2}$ Power, D., and Lundmark, M.: Labour Market Dynamics and the Development of the ICT Cluster in the Stockholm Region, in: Handbook of Research on Clusters, edited by: Karlsson, C., Aldershot, UK and Brookfield, US: Edward Elgar, in preparation, 2007.
}

question about exactly how biotechnological knowledge production takes place. According to the talented people argument, innovation policy should be focusing on designing attractive spaces in which creative people want to live, while the privileged sites argument instead focuses on figuring out how to design creative spaces (within which talent is, if not created, then at least realized at higher rates than elsewhere). In practical terms, this could involve either putting money in bohemian hotspots, family friendly spaces, international jazz festivals and similar features of an attractive urban landscape, or into the building of science parks and support of cluster projects. Implicit in this debate there is also the fundamental question about to which level of society innovation policy should be formulated, implemented and financed; a question to which the two sides of the debate offer quite different answers.

The point of departure for this paper is that we simply do not know, at the moment, which side of the debate is correct, but that we need to find out more about the seemingly paradoxical claims that the debate resonates. The talented people argument is too novel to have yet come up with any solid conclusions, and the strand of academia which promotes the privileged sites perspective has long been criticised for not producing enough evidence in support of its hypothesis. In this paper, a unique dataset is used to attempt to determine to what extent the two debating concepts, privileged sites and talented people, can explain what is going on in biotech landscapes in Sweden. The aim is not to settle this debate, but rather to use it as a framework for further study of one of the interesting paradoxes that have lately marked economic geographic literature and discussions.

The dataset, on which this study is based, is unique in the sense that it represents not a statistical sample but a universe. It contains every individual legally resident in Sweden over a period of thirteen years - from 1990 to 2002 - and includes, on top of personal attributes such as age and sex, information about individuals' three biggest income sources (in the following, "income" refers to the sum of these, while "side income" refers to the second and third income only - side income is therefore always a part of, not an addition to, the income variable); highest educational level; year when the highest education level was obtained; field of education; and, which sector of the economy the individual worked in. Also, the data are geo-coded so that there are two sets of coordinates (Swedish RT90) for each year - one set for the primary workplace and one for the residential address. From this data, the Swedish biotech elite are extracted. By using the coordinates, primary Swedish biotech sites are then identified. Using GIS and other means of analysis, this paper sets out to understand what constitutes success, of sites and people, in this system of elite biotech knowledge workers, and, of course, how sites and people affect each other.

The aim is twofold. On the one hand, this study gives an overview of how elite knowledge workers in the Swedish biotech sector are distributed spatially, and what 
characterizes them in terms of mobility, stickiness and so on. On the other hand, the present paper uses the geographical and economic data about this population to engage with the question of how these talented people are affected by their involvement in the privileged sites they come from, go to, glue together or make up.

This paper consists of four parts. Following this introduction, section two presents the data and provides an overview of the biotech system under study. In this first step of the two-fold analysis, the overall characteristics of the population are described and milieus of particular interest - the privileged sites - are identified. Section three then analyses various aspects of success for people and sites. Finally, section four draws conclusions and discusses these in relation to the aforementioned debating theories.

\section{The Swedish biotech system - people and sites}

Whilst the Swedish biotech system involves a wide range of essential workers - from cleaners to managers - at its innovative heart are highly educated scientists. In order to focus on this core group, data were extracted for everyone with a $\mathrm{PhD}$ in a biotech-related field who has been working in the Swedish biotech sector between the years 1995 and 2002. Since the data are geo-coded by workplaces, they also contain every site where members of this elite work. The present section serves to introduce the data, define the population under study and identify local biotech sites within the Swedish territory.

The full dataset, named PLACE, comes from Statistics Sweden (Statistiska Centralbyrån, SCB) and is an amalgamation of several Swedish registries. The primary object is the individual, and the dataset generally provides yearly snapshots (one value for each variable per year). Most of the data used here come from the Swedish tax authorities (originally from annual taxation reports filed by employers and employees). Another big part is education data, which originate from the Swedish education registry. This information is not survey data, but official data used for taxation purposes and other formal matters, which in turn means that it is relatively accurate compared to other statistical materials. However, despite their level of detail, scope and accuracy, the data underlying this study are not perfect. For example, the fact that each individual object has a coordinate does not guarantee that what we see in the data come from the particular place which the coordinate represents. Since the coordinates only represent yearly snapshots, an individual may very well carry out work in other places and move around temporarily as much as she or he likes, without necessarily leaving traces in the data. Also, when it comes to pinpointing biotech knowledge workers, categories concerning sector, fields of education and so on are broader than they appear at a glance. This being said, the data are pretty much as good as they get and if they do not contain traces, at least, of what the above- mentioned theories talk about, then we should seriously consider abandoning either the theories, or the idea of using this kind of quantitative data to empirically test their validity.

The population under study constitutes the elite of Swedish biotech workers, as defined by the following parameters: level of education; area of education; participation in the workforce (level of participation and sector); and income. To fit in the elite, individuals must: (i) have held a $\mathrm{PhD}$ in a relevant field (pharmacy; medicine; chemistry; biotechnology; biochemistry; toxicology; pharmacology; nutrition; or biology) already at the start of the period, i.e. in 1995; (ii) have been employed by their largest income source in either biotech industry/business ${ }^{3}$ or academia ${ }^{4}$; (iii) not have been unemployed for more than two years, or consecutive years; and, (iv) have earned, on average for each year of the period, no less than \$33000 U.S. (this amount represents roughly what a Swedish PhD-candidate earns in her or his final year) ${ }^{5}$.

Some particular groups which also fit these requirements have still been omitted since they would otherwise bias the results. One such group is medical practitioners with a $\mathrm{PhD}$ who, although some of these are likely to conduct biotech relevant research, would as a group mostly represent doctors exclusively working with the treatment of patients. PhDs working as experts in government agencies have also been excluded since they are not likely to be involved in knowledge production on the same scale as their peers in academia or industry. This is not to say that the omitted individuals should never be considered to be a part of Swedish biotech. Selections and definitions are made here for the purposes of this paper only. The basic principle behind all of the used requirements is that, as far as possible, only those knowledge workers whose professional performance primarily relies on an ability to produce and communicate advanced biotechnological knowledge should be included.

As we can see in Table 1, the final population consists of 1493 individuals, out of which $77 \%$ are men. The average income for the population is quite high - for men, it is about $41 \%$ higher, in 2002, than for the highest paid individuals

\footnotetext{
${ }^{3}$ Following the recommendation of Waxell et al. (2006, http://www.cind.uu.se/CIND\%20Research\%20Paper\%20Series/ CIND2006-4.pdf), but with a narrower focus on "knowledge production", this study uses the following of the Swedish industrial codes (2002): 24430 (Production of pharmaceutical drugs), 73101 (Science R\&D), 73103 (Medical R\&D), 73104 (Agricultural R\&D), 73105 (Cross-disciplinary R\&D based in Science), 51460 (Suppliers of medical equipment and pharmaceuticals).

${ }^{4}$ SNI 2002: 80301. Although this industrial classification code includes all university education and research, it does only provide biotech academics here since a field of education filter is also used.

${ }^{5} \mathrm{An}$ individual who earns less after completing a $\mathrm{PhD}$ than during her or his doctoral studies does arguably not deserve a spot in the elite. This threshold omits such individuals while at the same time allowing for a large range of incomes in the included group.
} 
Table 1. Basic characteristics of the Swedish biotech elite (Source: PLACE-database, SEK-USD conversion rates are for September 2006 throughout the paper, 7.4 kronor to the dollar).

\begin{tabular}{lll}
\hline & Men & Women \\
\hline Number & 1150 & 343 \\
mean age (2002) & 53 & 52 \\
mean annual income & 516270 SEK & 419318 SEK \\
(period) & Ca 70000 USD & Ca 57 000 USD \\
mean annual income & 611 133 SEK & 509379 SEK \\
(2002) & Ca 83000 USD & Ca 69 000 USD \\
mean annual side in- & 101984 SEK & 58917 SEK \\
come (period) & Ca 14000 USD & Ca 8000 USD \\
awarded PhD & Mean=1970 & Mean=1967 \\
& Median=1983 & Median=1986 \\
\hline
\end{tabular}

in Sweden's ten most common professions ${ }^{6}$; for women this number is $+18 \%$. Female members of the Swedish biotech elite earned $83 \%$ of what their male counterparts earned per year (2002). The side income proportion of the total income was twice as big for men as it was for women. Although rigid statistical analysis is required to correctly explain the overall income differences between the two groups, it seems as if it is caused to a large degree by the difference in side incomes ${ }^{7}$.

One way of defining where biotech knowledge production takes place is to assume that it does so where there are knowledge workers. Further, based on what we know about the interactive nature of innovation in general, we can assume that biotech knowledge production takes place at higher rates in agglomerations of knowledge workers than in places where only a few knowledge workers reside. In Fig. 1, the population under study is thus plotted by workplace coordinates. The figure contains four different maps in order to illustrate not only the spatial distribution of the Swedish biotech elite, but also to point out some of the different ways in which we can map the system. Starting in the top left corner, map A shows a plot in which each set of workplace coordinates is shown as a dot on a Swedish territorial map. In the figure, yearly snapshots between 1995 and 2002 are shown on top of each other. Map A reveals several agglomerations of knowledge workers, but since most individuals are so close to each other, the density of these agglomerations is invisible

\footnotetext{
${ }^{6}$ Source: http://www.scb.se/templates/tableOrChart__-_27555. $\operatorname{asp}(2006-09-28)$

${ }^{7}$ In the population under study, there is neither a significant difference concerning in which part of the economy men and women work, nor any significant age differences. There is a small difference in the amount of time men and women have been $\mathrm{PhDs}$ but considering the size of this difference it is hard to conclude that this would be the sole root of the differences in income. If we also take into account the proportion of men and women, it seems probable that some sort of gender discrimination is at play here; this is controlled for but not further examined in this paper.
}
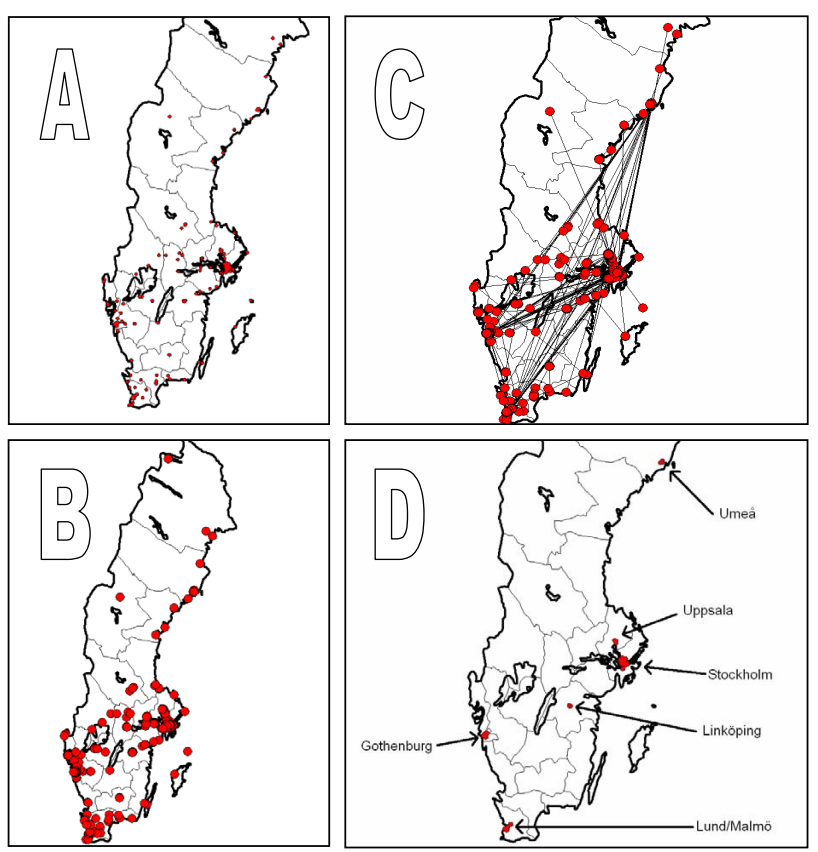

Fig. 1. Spatial distribution of the Swedish biotech elite (A), with a $5 \mathrm{~km}$ buffer (B), individual workplace mobility (C), and significant agglomerations of knowledge workers (D) (Source: PLACE DATA).

in this particular representation. In map B, therefore, a buffer ( $5 \mathrm{~km}$ in radius) has been added to each individual point. This buffer is then used to filter out points which do not belong to a significant density. In this case, the GIS program only kept individuals if their buffer intersected at least 20 other buffer zones per year (results in Map D). This particular number was calculated through a rank-size analysis and represents the lowest possible value that does not discriminate between agglomerations of similar sizes.

Map C shows every individual change of workplace coordinates between yearly snapshots. As can be seen in this map, the pattern of mobility is dominated by only a few links and nodes. A minimum of $83 \%$ (1997) and a maximum of $93 \%$ (1999) of the population is located in six urban areas: (i) Stockholm (minimum 365 - maximum 462 individuals); (ii) Uppsala (280-305); (iii) Lund/Malmö (69-202); (iv) Gothenburg (172-202); (v) Umeå (154-158); and, (vi) Linköping (74-79). The conclusion drawn from this analysis, the buffering in Map B and the mobility analysis in Map $\mathrm{C}$ is that we should talk about only six distinct biotech milieus in Sweden, as indicated in Map D. The most volatile is Lund/Malmö. In certain years of the period, a large number of individuals, who, in the year before or after were located in this area, all of a sudden lack Swedish coordinates. It seems likely that this is due to knowledge worker mobility across the strait to Denmark; unfortunately, however, we cannot say for sure with the available data. 
Figure 2 shows a topographical representation of the six Swedish biotech milieus (here termed Swedish BIO6) and mobility between them. The height of each pillar represents the average size of the knowledge worker population in that milieu and the shape of the pillar represents the geographical shape of the agglomeration. Movement is illustrated by proportionate arrows; the thicker the arrow, the more interaction - a threshold has been set to a minimum of two moves over the period. Movement is here defined as a change in workplace coordinates, between consecutive years. In a sense, the pattern in Fig. 2 is not surprising. The work of other scholars has indicated that Swedish biotech is concentrated to only a few urban university regions (see for example Waxell, 2005; Waxell and Malmberg, 2007). However, the relatively small number of moves between milieus is interesting to note. We often tend to perceive of knowledge workers as being more mobile than other groups. In this case, however, only a small portion of the population ever makes a non-local move. Even the largest link, Stockholm-Uppsala, represents only about $1 \%$ of the involved population each year, and yet these two cities are so close to each other that Statistics Sweden (SCB) in some definitions sees them as one single labour market. This mobility pattern can be interpreted to say that members of the Swedish biotech elite are rather localized and rarely move to a workplace in a different city. Considering the average age of the population under study, we can suspect that most of them have families and that this is the main reason for their low mobility (in Sweden a vast majority of family households have two members in the workforce).

It has long been debated whether Swedish biotech activities should be described as taking place in distinct local milieus and clusters, or as being part of the same national innovation system. Although this study does not cover all types of interaction, it seems to support a thesis which recent studies and anecdotal evidence have suggested, namely that there is rather little interaction between sub-milieus in the Swedish biotech system. In summary, the findings presented in this section indicate the following:

1. Members of the Swedish biotech elite are strongly agglomerated;

2. The spatial distribution of knowledge workers suggests that it makes sense to talk about six distinct biotech milieus in Sweden. These are either university cities or large urban areas, or both; and

3. Over the period, only a few members of the Swedish biotech elite ever moved between milieus.

\section{The effect of sites, co-workers, and mobility on indi- vidual success}

In the preceding section, it is noted that Swedish biotech knowledge workers are agglomerated in six significant milieus and that while most individuals are rather stationary, a

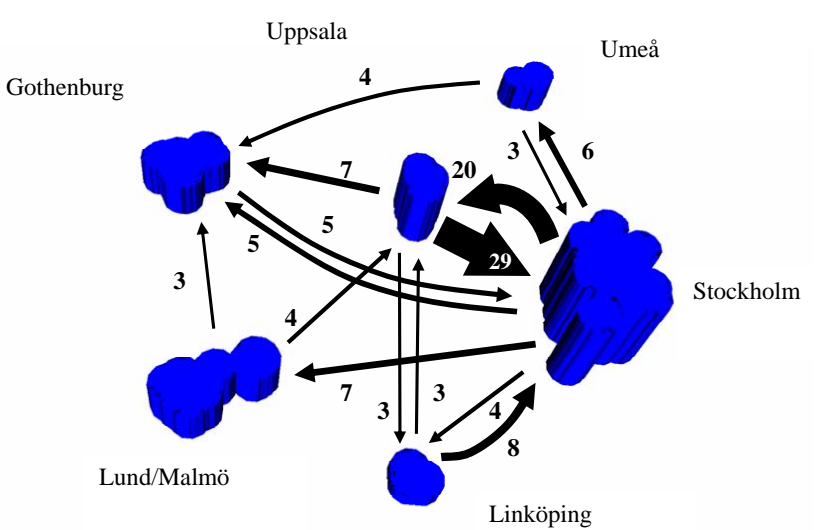

Fig. 2. Swedish BIO6 - relative size and mobility, total period (Source: PLACE DATA).

small portion move between these milieus. However, a series of questions are raised: To what extent are some individuals more successful than others and is this reflected in individual mobility, stickiness and other personal characteristics? Which is a more important determinant of individual successful performance: to be in a certain place or to be around certain people? Does it make sense, in the case of Swedish biotech, to talk about a system defined and shaped by elite knowledge workers, or should we instead talk about site success in classic terms, as the result of agglomeration effects and path dependency? In this section, three relationships are explored: (i) the relationship between individual success and milieu; (ii) the relationship between individual success and mobility; and, (iii) the relationship between individual success and co-location with the best of the best.

How should things like knowledge production, innovativeness and creativity, which make up knowledge worker performance, be measured and what traces would we expect these things to leave in statistical materials like the one at hand? Most previous studies use patent output, publishing data or the introduction of new products to measure innovation and knowledge production, while others simply resort to measuring input factors (assuming that there is a direct relationship between investment and payoff). While recognizing the contributions made through the use of all these methods, this study measures knowledge productivity by the income of knowledge workers.

This method has both pros and cons. There are three major strengths. First, each data point can be directly linked to an individual since income is a personal thing. Secondly, all knowledge workers have an income, which is not the case with patents or other indicators. Indeed, people tend to have a very low number of patents, which makes it hard to compare success rates (consider, for example, how big the difference is in knowledge productivity between those having, say, two patents and those having none). Finally, salaries are easy to compare. In the case of patent data, for example, 


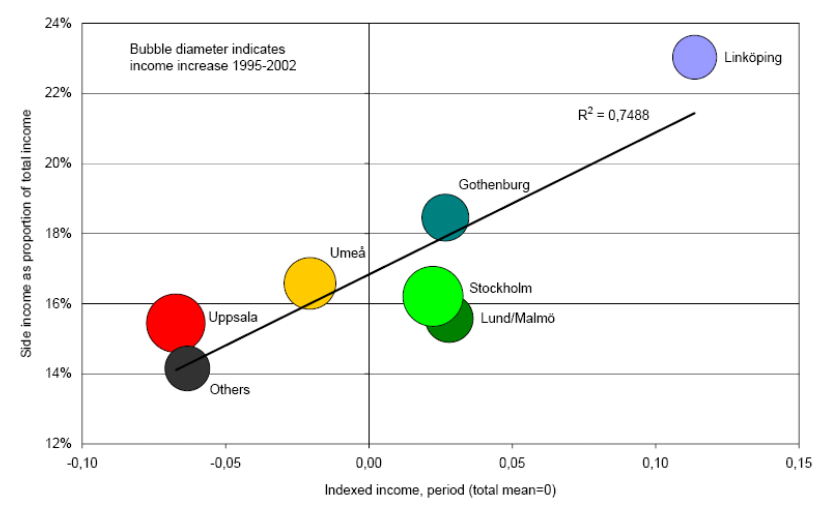

Fig. 3. Income differences between milieus, proportion of side income and income development for each milieu, 1995-2002 (Source: PLACE DATA).

there is no link between quantity and quality; one patent can be more important and valuable than a thousand, three publications more valuable to your career than twenty. Of course, there are ways to weight patents and publications, but such methods are always subject to complex sets of assumptions. Money, on the contrary, is always money. Income is mainly decided by how several parties view someone's competence, which lowers the bias compared to, for example, innovation surveys. If we ask people about innovation, we run the risk of getting overly positive answers since tasks that are new to an individual, but old in the firm or industry context, are often wrongly described as innovations.

In all these aspects, the income variable has some considerable advantages over patent-, publication- or survey data. Using income data, however, also involves some challenges. The fundamental assumption that the (knowledge) productivity of knowledge workers is measurably reflected in their income does not always hold true (consider, for instance, the income difference between men and women shown in Table 1); several factors may 'interfere' here, e.g. administrative and entrepreneurial skills. Also, if there is a relationship between knowledge productivity and income, it may still take time for it to come into effect. Finally, location always impacts individual income due to cost differences between regions. It is, for example, far more expensive to live in Stockholm than to live in any of the other agglomerations. Between nations this can be controlled for but within nations it is quite difficult. This study controls for sector, age and gender concentrations but the general problem remains unsolvable until good indexes for sub-national purchasing power have been developed.

It is important here to understand that the above arguments concerning the income variable assume a situation in which we have to choose between measurements. A carefully constructed combination of measurements - in other words some sort of innovation index - would be superior to any of the aforementioned measurements on their own. In this case, however, the construction of an index-type measurement is not possible due to regulation of data use.

Here, three tests will show how the income variable is affected by location, mobility and co-location. The first test looks for location impact by studying general differences in income between milieus, and also if moves to certain sites tend to effect incomes. The effect of mobility is studied by looking at differences between mobile and stationary individuals. The final test investigates the effect of co-location by following the best of the best (top $1 \%$ by income) and studying the effects, if any, of sharing a work place with members of this group. In the last section of this paper, the results of these tests are discussed in relation to economic geographic theory.

Seen over the entire study period, there are moderate differences between mean incomes in the milieus of Swedish BIO6. Also, the hierarchy is rather stable over time. With the exception of Lund/Malmö, members of Swedish BIO6 generally keep their place in the hierarchy over the period. Figure 3 shows differences in mean income, income increase, and side income as a proportion of total income. Knowledge workers in Linköping have the highest incomes on average, while individuals in Uppsala have the lowest. As the $R^{2}$ value in the figure indicates, there is a linear relationship between having a high secondary income and having a higher total income. This may seem obvious, at the individual level, but it is interesting to note the differences between milieus in frequency of side projects. Linköping-based knowledge workers seem to, for one reason or another, be engaged in more side activities than their colleagues in for example Uppsala. The four milieus in which knowledge workers have higher mean incomes consist of Sweden's three largest cities and the smaller city Linköping (which hosts a university specializing in technology). The high proportion of side income in the latter milieu could perhaps be explained by a concentration on technical disciplines of practical applicability, but it could also be the result of a more intricate milieu-aspect. Since mean income differences are so small, and since the side income variable seems to explain these differences quite well, it is hard to conclude, from this test, that there are any significant milieu effects on income.

If we instead look at individual moves, Linköping still looks alright, but Uppsala turns out to be the best place for biotech knowledge workers to move through. Moves from Stockholm to Uppsala, in particular, offer the biggest increase in income. While individuals who do not change city received average annual income increases of 25600 SEK over the period, those moving from Stockholm to Uppsala had a 136100 SEK average annual increase. Individuals moving the other way had 50000 SEK increases and the second best career move, from Uppsala to Linköping, gives a significantly smaller increase than the best; only 61500 SEK/year on average.

As Table 2 shows, moving to Uppsala generally gives the highest income increase and it also increases the "value" of 
future moves. Moving to Stockholm is also good, but knowledge workers better stay once they are there - leaving Stockholm generally involves a big income cut. Remembering that there is a high income reward for those moving from Stockholm to Uppsala, this low mean arguably further strengthens the notion that there is something about Uppsala. It is of course hard to say something certain about what these results mean. What we can say here is that it matters where knowledge workers are and how they move around, and that there seems to be a milieu effect that goes beyond general price differences between regions.

It seems true to say that the higher your mobility the better. However, mobility is generally low in the population under study. As Table 3 shows, the more moves an individual makes over the period, the more money she or he makes. While a single move does not generate any significant differences, those who have moved at least twice have higher incomes than the stationary group. Mobile individuals also tend to have higher side incomes. This presents us with a "the chicken or the egg" type of dilemma. The higher incomes among mobile individuals could be telling us that mobility equals success, but it could also mean that high-earning individuals change jobs more often.

Finally, co-location (same work place) with the very best (top $1 \%$ by income), does not seem to have a significant effect on individual incomes. The time a knowledge worker has been co-located with a member of the super-elite does have an impact, but it explains only a miniscule part of income differences (less than 5\%). This can mean two things: either co-location does not matter - in other words there is no spill-over effect of talent, or the method used here is not sensitive enough. It can also be a bit of both: co-location and cooperation probably has a positive effect, while colocation without cooperation probably has a negative effect, but the method used here does not distinguish between the two. While some knowledge workers are probably helped by cooperating with extremely talented people, some are probably suffering in the shadows such people cast. In summary, this section finds the following:

1. There are differences in mean income between milieus and these seem to be caused mainly by differences in side income frequency;

2. Uppsala stands out as a particularly good place to pass through for members of the Swedish biotech elite. Linköping is a good alternative, while Stockholm only has a positive effect on the individual incomes of those moving there;

3. Mobility in general has a positive effect on income but few members of the Swedish biotech elite actually move; and,

4. Being in the same workplace as members of the absolute elite gives such a small reward in terms of income that it is hard to conclude that it has an effect at all.
Table 2. Mean annual income increase as a result of individuals moving to/from Swedish BIO6 milieus (Source: PLACE DATA).

\begin{tabular}{llll}
\hline Moving to: & $\begin{array}{l}\text { Mean annual } \\
\text { income } \\
\text { increase }\end{array}$ & Moving from: & $\begin{array}{l}\text { Mean annual } \\
\text { income } \\
\text { increase }\end{array}$ \\
\hline Uppsala & 35900 & Linköping & 35000 \\
Stockholm & 29600 & Uppsala & 34300 \\
Linköping & 21500 & Lund & 29200 \\
Umeå & 19100 & Gothenburg & 17100 \\
Lund/Malmö & 14900 & Umeå & 10900 \\
Gothenburg & 4100 & Stockholm & -5900
\end{tabular}

Table 3. The relationship between mobility and mean annual income/side income proportion (Source: PLACE DATA).

\begin{tabular}{cccc}
\hline $\begin{array}{c}\text { Number } \\
\text { of moves }\end{array}$ & Individuals & $\begin{array}{c}\text { Mean annual } \\
\text { income }\end{array}$ & $\begin{array}{c}\text { Side income } \\
\text { proportion }\end{array}$ \\
\hline 0 & 1006 & 487863 & $17 \%$ \\
1 & 191 & 482972 & $19 \%$ \\
2 & 269 & 515496 & $24 \%$ \\
3 & 22 & 555147 & $27 \%$ \\
4 & 4 & 673703 & $39 \%$ \\
5 & 1 & 923938 & $40 \%$ \\
\hline
\end{tabular}

\section{Conclusions}

In almost every developed country, we can find regions with a more or less developed strategy to become the next hotspot for the biotech industry. While it is rather obvious that only a few can actually reach this goal, there seems to be some truth in the notion that success depends on local events and structures. As discussed in the introduction to this paper, knowledge workers are reclaiming centre stage in theoretical and political discussions about regional competitiveness and economic growth, and this is revitalizing one of geography's most classic questions: how are human beings affected by the environment in which they live and vice versa?

In light of the literature on clusters, innovation systems and talent, the findings of this study give support to some arguments and render some less plausible. In the preceding sections, we see that members of the Swedish biotech elite are strongly agglomerated and immobile, but that they are rewarded for spending time in more than one milieu and for moving around in general. This is an interesting paradox. Yet, considering the polarized nature of the privileged sites versus talented people debate, we should perhaps not be surprised to find contradictory traces in the data. On the contrary, we should always be surprised if we find overwhelming evidence supporting only one side of a debate that divides competent research communities. We must also remember that economic geographic theory generally is forgiving towards paradoxes. It is in the nature of space itself to make 
room for multiple truths and commonly what is true evolves over time. And what is true in principle always changes when it is played out and takes place. Although we might often focus on gatherings of different sorts, space also plays the important role of keeping things apart. Moving around is not simply about leaving one place and arriving at another. The relationship between old and new home-places lives on also after the move. Many movers feel like they belong neither in their old space, nor in their new; while moving somewhere is definitely to learn a new way of life, it is also about forgetting an old.

It is evident here that talented knowledge workers are rewarded for mobility and that going to several milieus is better than staying in one. This supports the notion that knowledge production and innovation is about movement, heterogeneity, variety and diversity, rather than about specialization and stickiness. To this point, the present study advocates one of the underlying ideas of the talented people argument, namely that mobile creative people, with diverse backgrounds, are good for innovation processes. The problem, however, is that what we see in the data is a pattern of agglomerated, stuckin-the-mud individuals. Biotech knowledge workers do not move between regions. This delivers a blow to the idea that regional competitiveness depends on an ability to attract and retain talent - at least in the context of Swedish biotech, and when it comes to mature talent. What we see here is that once knowledge workers get their PhDs, they generally stay in place. Retaining talent, therefore, seems to be a default function of local milieus. Since the defining feature of all Swedish BIO6 milieus is that they host at least one top university, we can further assume that the attraction of talent takes place when members-to-be of the talented elite choose university - before these people have developed either a distinguished taste for urban culture or a wallet for cool urban life. Despite the fact that knowledge worker mobility, as this study shows, is a significant booster of knowledge worker incomes, the idea that people will ever be as mobile as the current version of the talented people approach generally assumes does not seem plausible.

The results do support the privileged sites explanation but only to a limited extent. Biotech knowledge workers do agglomerate in special milieus. There is, however, only a small difference in income between milieus, which, in turn, would suggest that there are no significant place-specific synergy effects at play here. Common for all Swedish BIO6 milieus is that they have good universities, but differences in the performance of these, in terms of university rankings and publications, do not seem to affect income levels to a noticeable extent. The only clear effect seen here is that Uppsala is a good place to pass through for those wanting to make a lucrative biotech career. Perhaps all of this should be interpreted to say that we should go back to basics when formulating regional biotech innovation policy - like building attractive universities and a diverse labour market for biotech workers. Within such basic frameworks there would also be room for the talented people argument, since the basic problem of this argument, according to the study at hand, is that people who have reached a certain level of education and experience have also developed a high degree of stickiness. While it is not likely, in the case of biotech landscapes, that there is a relationship between the attractiveness of urban regions on the one hand and the spatial distribution of knowledge workers on the other, it seems quite obvious that the presence of fundamental things like universities and other types of biotechnological infrastructure matters.

In a sense, there is some irony in discussing the relationship between talented people and privileged sites in relation to biotechnology since this field is starting to seriously challenge the very distinction between human being and milieu. At the same time, however, the nature of this technology represents the essence of why economic geographers believe that knowledge production is a fundamentally localized process. This essence lies in the assumption that new knowledge is produced at the interface between competences that are different enough to add something to each other while at the same time being similar enough to be compatible. As Storper and Venables (2004) have shown, face-to-face contact is a superior communications technology when it comes to bridging gaps between competences. Thus, we can assume that the more specialised each 'ingoing' body of knowledge is, the more important local interaction is. Biotech is clearly a hybrid which draws its potential from combining very complex bodies of knowledge, which in turn means that it should, theoretically speaking, be both a highly localized phenomenon and one depending on talented people.

Acknowledgements. I am especially grateful to J. Östh for helping me with the dataset. As always, my supervisors A. Malmberg and D. Power were dedicated readers and first-class commentators. I would also like to thank M. Hoyler and H. Jöns, as well as the anonymous referees, for their valuable input. Usual disclaimers apply.

Edited by: H. Jöns

\section{References}

Almeida, P., and Kogut, B.: Localization of Knowledge and the Mobility of Engineers in Regional Networks, Manage. Sci., 45(7), 905-917, 1999.

Asheim, B.: Industrial districts as "learning regions": a condition for prosperity, European Planning Studies, 4, 379-400, 1996.

Braczyk, H.-J., Cooke, P., and Heidenreich, M. (Eds.): Regional Innovation Systems, London: UCL Press, 1998.

Cooke, P.: Regional Innovation Systems: General Findings and Some New Evidence from Biotechnology Clusters, J. Technol. Transfer, 27(1), 133-145, 2002.

Edquist, C.: Systems of innovation: technologies, institutions and organizations, Science, technology and the international political economy, London: Pinter, 1997.

Florida, R.: The economic geography of talent, Ann. Assoc. Am. Geogr., 92(4), 743-755, $2002 \mathrm{a}$. 
Florida, R.: The rise of the creative class: and how it's transforming work, leisure, community and everyday life, New York: Basic Books, 2002b.

Hallin, G. and Östhol, A.: On the growth policy agenda, Stockholm: ITPS, 2004.

Lundvall, B.-Å.: National Systems of Innovation: towards a theory of innovation and interactive learning, London: Pinter, 1992.

Lundvall, B.-Å.: National Innovation Systems: analytical concept and development tool, in: DRUID Tenth Anniversary Summer Conference, Copenhagen Business School, 2005.

Malmberg, A.: Klusterdynamik och regional näringslivsutveckling - begreppsdiskussion och forskningsöversikt, ITPS rapportserie A2002:008, Stockholm: ITPS, 2002.

Malmberg, A, and P Maskell. 1997. Towards an explanation of regional specialisation and industry agglomeration. European Planning Studies 5:1-15.

Marshall, A: Industrial Organization, Continued. The Concentration of Specialized Industries in particular Localities. In Principles of Economics, Book IV, Chapter X, edited by: Marshall, A., London: Macmillan, 1920/1960.

Maskell, P., and Malmberg, A.: Localised learning and industrial competitiveness, Cambridge J. Econ., 23, 167-185, 1999.
Mattsson, H.: How Does Knowledge Production Take Place? On Locating and Mapping Science and Similar Unruly Activities, in: Taking Place, Locating Science, Technology, and Business Studies, edited by: Baraldi, E., Fors, H., and Houltz, A., Sagamore Beach, MA: Science History Publications, 2006.

Porter, M.: Clusters and the new economics of competition, Harvard Business Review Nov-Dec, 77-90, 1998.

Rinaldi, A.: More than the sum of their parts?, EMBO reports, 7(2), 133-136, 2006.

Scott, A. J.: Metropolis: From the Division of Labor to Urban Form, Los Angeles: University of California Press, 1988.

Storper, M. and Venables, A.: Buzz: face-to-face contact and the urban economy, J. Econ. Geogr., 4, 351-370, 2004.

Storper, M.: The Limits to Globalization: Technology Districts and International Trade, Los Angeles: University of California, 1992.

Waxell, A.: The Uppsala Biotech Cluster. Economic-Geographical Studies of Interaction, Knowledge Spill-over and Labour Mobility, Geografiska regionstudier 62, Uppsala: Uppsala University, 2005.

Waxell, A. and Malmberg, A.: What is global and what is local in knowledge-creating interaction? The case of the biotech cluster in Uppsala, Sweden, Entrep. Region. Dev., 19, 137-159, 2007. 